\title{
Financial Management of Micro, Small and Medium Enterprises during COVID Times-Analytical Review with reference to Indian MSMEs
}

\author{
Abhijit Kelkar* \\ Associate Professor- University of Fujairah, United Arab Emirates \\ *Corresponding Author: Abhijit Kelkar, Associate Professor- University of Fujairah, United Arab Emirates.
}

Received: February 07, 2022; Published: February 28, 2022

DOI: 10.55162/MCET.02.020

\begin{abstract}
COVID-19 outburst has harmed not only the Indian economy's economic and social activities, but also the global economy as a whole. Cushioning levels of shocks especially for financial downs remain to be restricted for MSMEs. The main reason is due to limited potential for raising and management of funds. This generates a significant impact on MSMEs. This paper seeks to evaluate MSMEs' contribution towards the Indian economy along with analyzing the barriers and challenges that existed prior to and during the COVID period. Challenges were indeed in presence before COVID 19 also but during and post COVID 19, their intensity, severity and scope have changed a lot. In addition, a few more are also emerged newly. To analyze the overall effect and impact of these challenges, a range of descriptive statistics along with correlation and co-integration is used. Cointegration is used to analyze the relation among variables such the amount of MSMEs, investment amount, employment, etc. output. This pandemic has crashed into MSMEs like a tons of bricks. COVID 19 remains to be a huge uncertainty and with the understood scope of this uncertainty so far, government must establish a continuous monitoring mechanism and announce early corrective actions to restore confidence in the MSMEs sector. MSMEs should be encouraged to connect to the internet market and fiscal incentives for this sector should also be strengthened. The Indian government should take a variety of initiatives to improve SMEs in India and achieve the goal of making India self-sufficient.
\end{abstract}

\section{Introduction}

COVID-19 massive spread caused havoc and confusion on all sectors including Micro, Small and Medium Enterprises commonly called as MSMEs. The untested lockdown chocked the MSME sector's economic activity causing unfavorable shocks such as a lack of raw material procurement, reduced production and delivery of finished products including shortage of workers in especially manufacturing process. The effects are numerous some of which are detected in terms of quantification of losses whereas some remain to be earthed till date. To name a few, job losses, reduced revenue production, decreased sales, and a fall in working-class income. (Hariharan et al., 2021).

MSMEs have been playing a crucial role in India's economic and social development since they rely on traditional hereditary skills to produce the goods with extensive use of available resources in the area (Indrakumar, 2020).

MSMEs also broaden their sphere of impact in rural and underdeveloped regions by fostering entrepreneurship in resource-poor communities and manufacturing over 6,000 high-quality items for national and international markets. MSMEs having gained in prominence in recent years have resulted in the form of their consistent contribution to creating jobs and income development via export earnings along with their ability to adapt to market changes through creative practices in both the locally and globally realms (World Bank Group, 2018). The 73rd round of the National Sample Survey (NSS) was conducted in 2015-2016, and it found that, MSMEs were the sole sector to generate large employment prospects with 6.34 Crore MSME units generating 11.10 Crore jobs. By strengthening 
non-agricultural livelihoods and attracting new investments to the sector, it creates backward and forward economic connections (Ministry of MSMEs, 2018-2019).

For its far-reaching effects on the economy, the MSMEs sector has been largely regarded as the backbone of the Indian economy. However, with the impact of the Covid 19 has disturbed the well balanced equation of the MSME sector forcing them to rethink on the strategies for their long term survivals. The prospect of a lockdown has been evident there in MSMEs sector, resulting in a versatility of problems including financial crises, demand, supply chain concerns and also the freezing of import and export opportunities. (Banu \& Suresh, 2020). To overcome health crisis worries \& maintain its development trajectory, this business demands quick stimulation. The government has expressed its concern by providing monetary and fiscal support to stimulate economic activity in the industry.

Every economy has its own set of rules for classifying small and medium businesses. Most nations regard small and medium enterprises to be the same; the main distinction is between small, medium, and big businesses. Differentiating criteria have included the number of employees, annual sales, turnover, and capital investment in equipment and machinery. The MSMEs Development Act of 2006 defined MSMEs in India. On June 1, 2020, the Cabinet Committee authorized a change to the definition of MSMEs in order to address the COVID-19 pandemic. Both investment and turnover will be utilized as harmonized norms for MSMEs categorization in India as a result of this.

New entrepreneurs may be attracted to the sector as a consequence of the amended definition, resulting in increased investment, production, and employment in the economy (Vaishnav \& Surya, 2020).

Comparison of Criteria Used for Defining MSMEs.

\begin{tabular}{|c|c|c|c|}
\hline \multicolumn{4}{|l|}{ Definition of MSMEs } \\
\hline \multicolumn{4}{|c|}{ MSMEs Classification, 2006} \\
\hline \multicolumn{4}{|c|}{ Criteria: Investment in Plant and Machinery Equipment } \\
\hline Classification & Micro & Small & Medium \\
\hline Manufacturing enterprise & Investment < ₹25 lakh & Investment $<₹ 5$ crore & Investment $<₹ \mid 0$ crore \\
\hline Service enterprise & Investment < ₹।0 lakh & Investment $<₹ 2$ crore & Investment $<$ ₹5 crore \\
\hline \multicolumn{4}{|c|}{ Revised MSMEs Classification, 2020} \\
\hline \multicolumn{4}{|c|}{ Composite Criteria: Investment and Annual Turnover } \\
\hline Classification & Micro & Small & Medium \\
\hline Manufacturing and service & $\begin{array}{c}\text { Investment }<₹ \mid \text { crore } \\
\text { and turnover }<₹ 5 \text { crore }\end{array}$ & $\begin{array}{l}\text { Investment }<₹ 10 \text { crore } \\
\text { and turnover }<₹ 50 \text { crore }\end{array}$ & $\begin{array}{c}\text { Investment }<₹ 20 \text { crore } \\
\text { and turnover }<₹ 100 \\
\text { crore }\end{array}$ \\
\hline
\end{tabular}

The Micro, Small and Medium-sized Enterprises (MSMEs) sector contributes significantly to India's economic growth. Prior to the COVID-19, sector was facing low and slow growth owing to a slew of issues including a lack of financial backing, adequate infrastructure and innovative technology. In addition, the process of demonetization (2016) and the Goods and Services Tax (GST) (2017) exacerbated the difficulties. As the majority of MSMEs rely on unskilled labourers from rural areas, minor issues have a greater impact on them. Needless to mention the health crisis of the manpower puts their potential and sustainability of MSMEs in jeopardy.

The operating environment for MSMEs has altered as a result of COVID-19. In MSMEs sector, especially those smallest enterprises, were the worst hit by the most severe lockout to prevent a COVID-19 problem from spreading. Supply chain issues including crossstate or cross-country raw material imports result from the abrupt notification to implement all COVID-19 emergency measures with in production process, consumer fear, demand side problems, price rises, malfunctioning, reduced profit and so on. This has resulted in unemployment, procurement of perishable products, monetary crunch.

To 55 percent job losses, production falling from such an average of 75 percent capacity to just 11 percent, a loss of 17.2 percent of annual sales, delays in receiving raw materials, a lowered capacity to afford wages, a labour shortage, and a lack of access to credit, the MSMEs industry is in a worse possible shape. By the end of 2020 , the situation was like $70 \%$ of firms feared about their capacity to

Citation: Abhijit Kelkar. "Financial Management of Micro, Small and Medium Enterprises during COVID Times - Analytical Review with reference to Indian MSMEs". Medicon Engineering Themes 2.3 (2022): 12-25. 
survive the crisis not for more than three months if the lockdown continued. Even the smallest organization will be shut down. (Ghosh, 2020; Rathore, 2020; WTO, 2020).

According to The Hindu, 71 percent of 5,000 MSMEs surveyed by the All India Manufacturers Organization are unable to pay their employees' salaries. In India, roughly $25 \%$ of businesses will be forced to close if the lockdown lasts longer than 4 weeks, and $43 \%$ would be forced to close if the lockdown lasts longer than 8 weeks (The Hindu, 2020). Unfortunately, the lockdown phase got continued with some relaxation. For MSMEs to operate to their fullest potential, partial lockdown and complete lockdown were same. Surprisingly, the Lockdown with a few relaxations worsened the situation.

Cash being a crucial current asset, remains to be an important element of the transaction system of Indian economy. Especially with regard to the MSME sector, most of the payments were in the form of cash disbursements including payments on account of wages, carriages, raw materials and so on. Due to lack of / unavailability of the digital framework as well as the unawareness and illiteracy of the receivers, the MSMEs manage most of their disbursements through cash only. This lead to a financial crisis including cash crunch for MSMEs. In absence of the adequate funds at the discretion of the MSMEs, they were and are forced to close down. Around 55 percent of electronic component Chinese imports have been limited to $20 \%$ for coronavirus and shutdown. And get out of this bind, India is reducing its dependency on China and increasing domestic production (Prasad \& Mondal, 2020). There is a limited demand for eatables, hotels and restaurants industry for more than 5 months. People were also avoiding travel. Textile industry output was decreasing day by day owing to a lack of imported raw materials during in the lockdown signaling that manufacturing may be halted. For example, Sambalpuri, Maniabandha sarees, and so on. The COVID-19 has an out-of-the-ordinary impact on society, economy, budgets, deficits and financial markets in general. Needless to mention, it has impacted the global economy as a whole as well. To add a fuel to the already burning fire, the uncoordinated and unsynchronized lockdown along with the varying conditions of relaxations by the Central and State Governments have led to a disturbed supply chain and logistics management (Sipahi, 2020).

COVID-19 has also had some favorable effects on MSMEs. The movement of goods has been halted throughout the shutdown. MSMEs strive to be self-sufficient and create items within the nation. MSME is an excellent chance to create hand sanitizer, face masks, and other similar products. Some firms benefit, such as those that deal with necessities for survival. People want critical products more than they require, resulting in a price increase owing to a lack of supply. Individual mobility has been prohibited in containment zones, and in this crucial scenario, certain businesses dealing with packaged goods have the chance to create a healthy society by providing home delivery.

The Indian government took significant attempts to revitalize MSMEs during COVID-19 crisis. The Emergency Credit Line Guarantee Scheme, one largest fiscal component of the Aatmanirbhar Bharat Abhiyan package of 20 LakhCrores, was unveiled either by government in May. The package's main goal is to improve enterprises, with a particular focus on SMEs. The following are the initiatives:

a. MSMEs have now been categorized based on both yearly income and investment constraints. Enhanced this same investment limit for micro units in the manufacturing sector from Rs. 25 Lakh to Rs. 1 Crore, for small units in the manufacturing sector from Rs. 25 Lakh to Rs. 5 Crore, and in the service sector from Rs. 10 Lakh to Rs. 2 Crore, but it is now Rs. 10 Crore, and for medium units in the manufacturing sector from Rs. 5 Crore to Rs. 10 Crore, but it is now Rs. 10 Crore. but it is now Rs. 50 Crore in both manufacturing and services sectors Introduced new turnover requirements of 5 Crore for micro, 50 Crore for small, and 100 Crore for medium in both manufacturing and services in terms of investment and turnover.

b. The RBI also took other stepssuch as lowering the repo rate allowing the bank to lend at a lower cost assisting the MSMEs sector. The State Bank of India set a target of allocating 700 Crore to MSMEs in Mumbai.

c. To help the ailing MSMEs sector, the government issued 3 LakhCrore collateral-free automatic loan that it did not return for a year. The purpose was to assist around 45 Lakh MSMEs throughout the country in resuming their operations and safeguarding jobs. The government also decided to finance a subordinated debt of 20,000 Crore to stressed MSMEs. Accordingly, a fund has been established to invest 50,000 Crore in the MSMEs sector.

d. For strategies to succeed \& supply in government contracts, global bids will indeed be prohibited for government procurement

Citation: Abhijit Kelkar. "Financial Management of Micro, Small and Medium Enterprises during COVID Times - Analytical Review with reference to Indian MSMEs". Medicon Engineering Themes 2.3 (2022): 12-25. 
up to 200 Crore that would aid 'Make in India' \& develop toward self-reliance. This is initiated with an objective of giving MSMEs a boosting for existence and increasing their businesses. All dues to MSMEs would be paid within 45 days by the Indian government and central public sector undertakings (CPSEs).

e. E-market connection for MSMEs has begun as an alternative for trade fairs and exhibits. Fintech is expected to enhance transaction-based financing for MSMEs. This is in order to overcome the difficulties faced during the Covid 19 times in marketing and liquidity.

f. To ease the financial load on businesses, the government has agreed to provide PF and EPF assistance to the both businesses and employees via offering a liquidity relief of Rs 6,750 Crore. To provide liquidity there in hands of consumers and producers, EPFO reduced workers and employers PF payments from 12 percent to $10 \%$ for any and all official enterprises, although employer contributions would remain at 12 percent for CPSEs and state PSUs. Around 6.5 Lakh employers and 4.3 Crore employees benefit from the government's assistance. This incentive is also available to workers who are not qualified for EPF assistance of 24 percent under the PM Garib Kalyan Package.

g. Similarly, the government promised a $25 \%$ cut in the TDS rate for SMEs, NBFCs, and TCS in terms of putting more wealth into the hands of taxpayers. As part of direct tax measures, this same income-tax return for FY 2019-2020 will indeed be extended from 31st July 2020 to 30th November 2020, and also the tax audit will indeed be extended from 30th September 2020 to 31 st October 2020. As per government, any pending refunds to charitable trusts, non-corporate firms and professions, such as proprietorships, partnerships, LLPs, including co-operatives, would be issued immediately.

Financing is a major impediment to the growth of micro and small companies in many countries. MSMEs account for nearly 99 percent of all firms in India, with 63 million MSMEs spread across numerous industries and geographical areas. MSMEs finance has been consistently listed as a priority among India's economic goals. Despite improvements in financial infrastructure throughout time, access to funding for SMEs remains a barrier in many nations.

Micro and small enterprises, in particular, experience a funding gap since they have a tougher time acquiring loans from conventional financial institutions. This is primarily due to information asymmetry, a lack of prior credit history, formal paperwork, and other factors that make lenders reluctant to lend to these consumers. Even if they are approved for financing, it usually takes a long time to process and requires hard collateral such as moveable property and other time-consuming documentation.

These are challenging times, and MSMEs must prepare carefully to manage their finances and businesses. This research paper will provide ways through which MSMEs can plan to tide over the pandemic.

In this scenario, it is crucial to cover the ongoing situation for the MSMEs and the probable inputs to the MSMEs and Government for providing the financial and non-financial assistance. The economic restrictions imposed as a result of the COVID-19 crisis have suffocated a large number of firms, particularly micro, small, and medium enterprises (MSMEs), to the point of permanent closure. They account for roughly $30 \%$ of India's GDP and nearly half of its exports. As a result, the prudence with which MSMEs handle themselves through this crisis with government aid will go on to play a decisive part in their survival tale. The government has taken some steps to help MSMEs, but much more has to be done in terms of providing adequate and timely financing.

These are challenging times, and MSMEs must prepare carefully to manage their finances and businesses. This research paper will provide ways through which MSMEs can plan to tide over the pandemic.

Since days of National Planning Committee, it was emphasized the MSMEs would play an important role; as a result, it must always be encouraged on a long-term basis, and their major difficulties must always be addressed. Its rise of both the MSMEs sector, which account for the majority of India's manufacturing output, is a precondition for the growth of a rising economy like India (Eniola \& Entebang, 2015). In comparison to the industrial sector, the MSMEs sector has grown at a faster rate in recent years. The sector's most significant asset is its potential for employment at a minimal resource basis. After the primary agricultural industry, with terms from both self-employment \& jobs, the MSMEs sector offers one of most opportunities. The MSMEs sector made a significant contribution to job

Citation: Abhijit Kelkar. "Financial Management of Micro, Small and Medium Enterprises during COVID Times - Analytical Review with reference to Indian MSMEs". Medicon Engineering Themes 2.3 (2022): 12-25. 
creation and rural industrialization, as well as encouraging entrepreneurial impulse and reducing regional inequities (Bhuyan, 2016). Because communication obstacles have yet to be removed, the ministry of MSMEs is responsible for assisting state governments in supporting the growth and development of MSMEs so that they may compete in the changing global landscape (Ali \& Husain, 2014).

In terms of creating infrastructure, creating jobs, inventing new skills and proficiency, ensuring equitable regional integration, continuing to develop backward areas, helping the economy self-sufficient thru the import - substituting, and enabling this same nation's design process, the above sector does have enormous investment potential. At same time, due to the size, breadth of operations, poor financial executive resources, or, more significantly, its incapacity to cope with something so unexpected, it MSMEs sector is perhaps the most susceptible in the COVID-19 pandemic age (Sipahi, 2020). Due to interruptions in demand chain issues in the production process, as well as raw material \& labour availability, COVID-19 seems to have had a substantial negative impact on the MSMEs sector, resulting in decreased revenue generating (Singh, 2020). Businesses are forced to limit their company operations or migrate from non-essential to crucial commodities including such masks, PPE kits, sanitizers, as well as other products leading to a shortage of financial strength, raw material availability, labour shortages, and other causes (Tripathy, 2020). According to a poll performed by the All-India Manufacturers Organization on MSMEs, self-employed MSME units, which account for 35 percent of the MSMEs sector, have little possibility of reviving their operations because they have already begun the process of shutting down (Tripathy \& Bisoyi, 2021). Due to the pandemic aftermath crisis, garment manufacturing firms in the export sector suffered a commercial loss of about 150 Crore from March to May 2020. (Roy, 2020). India's leather sector is estimated to lose \$1.5 billion in exports due to the worldwide market slump. Payments to employees, payments on fixed variables such as electricity, rent, and interest, limited cash flow within economy, labor force mobility, controlled material supply, as well as other concerns are now all producing problems for MSMEs (Tripathy \& Bisoyi, 2021).

Countries must strengthen their businesses in the MSMEs sector in order to propel the economy ahead (Sipahi, 2020). To defend MSMEs, the government has primarily implemented emergency stimulus but instead precautionary measures, such as liquidity support to address cash flow issues, job retention thru all the different programmes, as well as business continuity, and also measures to expand trade opportunities besides strengthening one 's capacities. (Chauhan, 2020; WTO, 2020). There are difficulties in implementing the relief measures since India's true difficulty would be identifying the 63.4 million unregistered MSMEs, the majority of which are micro-businesses (Prasad \& Mondal, 2020). It has also been discovered that the majority of the government's policy instruments do not directly target MSME units; rather, a more comprehensive policy action to reorganize the backbone is required (Reddy et al., 2020). The federal government's relief efforts would not be adequate to revive the MSMEs sector, which has collapsed (Raney, 2020). As a result, the government must ensure that every player in the MSMEs sector is reached through adequate procedures and tracking methods (Ghosh, 2020).

Despite an abundance of studies just on MSMEs sector and also its importance for the development of India, the onset of such a crisis seems to have had a negative impact on MSME units throughout terms of production, distribution, investment, employment, revenue generation, social integration, monetary needs, and so on, and studies related to the evaluation of COVID-19 on MSMEs inside the Indian context appear to really be partial. Furthermore, evaluation of the government's policy responses and revival measures is particularly limited. The article would identify a statistically significant correlation among some of the major aspects of the MSMEs sector, including the number of MSMEs, investment, production, and employment, and will provide a clear assessment of both the long-run link these variables. By terms of combining the COVID-19 experimental scenario the with MSMEs sector, this research will just be crucial.

\section{Research Primary Objectives}

- To calculate contribution of MSMEs toward the Indian economy in terms of output, employment, income, investment and export.

- To understand the issues prior to and post Covid 19 scenario in MSME sector.

- To investigate and analyze government's remedial policy measures to revitalize the MSMEs sector.

- To understand the financial management of MSMEs during COVID times. 


\section{Research Methodology}

Research Paper is primarily based on the Secondary sources included the Ministry of MSMEs' annual report, data from of the Central Statistics Office, Ministry of Statistics and Programme Implementation, RBI, and also the Press Information Bureau (PIB)/Directorate General of Commercial Intelligence as well as Statistics (DGCIS), data from CIBIL, this same Regional Development Bank's Report, and press releases from numerous news agencies, among many others.

The variables used to calculate the suggested connection are the number of MSMEs, employment, investment, and production, all of which have been compiled during the years 1992-1993. As the stated variables are not in the same set-up as before in subsequent yearly reports from the Ministry of MSMEs, the study's analytical period was limited to 2015-2016.

Descriptive statistics, correlation, and co-integration analysis were used in this study. Correlation is a technique for determining the degree of relationship between two variables. The technique of co-integration has been used to determine whether or not two variables have a long-term connection. As a consequence, time series data was utilized to determine the long-term relationship and trend between the variables. Some statistical procedures utilized have been the unit root test, improved Dickey-Fuller test, Johansen's co-integration test, the trace test, as well as the maximum eigenvalue test, which have been computed to use the statistical software programme E-views 7.

The data collected from the secondary sources are treated and analyzed in order to apply the statistical tools. This supported the robust interpretation of the data and recommendations and suggestions were natural outcomes from the analysis.

\section{Data Collection}

MSMEs, particularly in developing nations, play a critical and strategic role. MSMEs' position in the Indian economy has been specified from the start of the planned economy in 1951. (Vashisht et al., 2016). MSMEs in India produce nearly 6,000 different commodities, ranging from traditional to highly advanced items. In comparison to India's entire industrial sector, the MSMEs sector has grown at a faster rate in recent years. The average growth rate of the MSMEs sector was 13\%. Nearly 114 million individuals were engaged in the MSMEs industry (Sipahi, 2020). MSME employs the second-largest number of people after agriculture "(Kishore, 2016; Raney, 2020; Vaishnav \& Surya, 2020)". Table 2 highlights several key metrics that may be used to track the MSMEs sector's successful advancements.

“Contribution of MSMESs in Country's Economy at the Current Price (in rupees Crore).”

\begin{tabular}{|lcccccc|}
\hline Year & $\begin{array}{c}\text { MSMEs } \\
\text { GVA }\end{array}$ & $\begin{array}{c}\text { Growth } \\
(\%)\end{array}$ & Total GVA & $\begin{array}{c}\text { Share of MSMEs } \\
\text { in GVA (\%) }\end{array}$ & $\begin{array}{c}\text { Total } \\
\text { GDP }\end{array}$ & $\begin{array}{c}\text { Share of MSMEs } \\
\text { in GDP (\%) }\end{array}$ \\
\hline $2011-2012$ & $2,622,574$ & - & $8,106,946$ & 32.35 & $8,736,329$ & 30.0 \\
$2012-2013$ & $3,020,528$ & 15.17 & $9,202,692$ & 32.82 & $9,944,013$ & 30.4 \\
$2013-2014$ & $3,389,922$ & 12.23 & $10,363,153$ & 32.71 & $11,233,522$ & 30.20 \\
$2014-2015$ & $3,658,196$ & 7.91 & $11,504,279$ & 31.8 & $12,467,958$ & 29.34 \\
$2015-2016$ & $4,059,660$ & 10.97 & $12,574,499$ & 32.28 & $13,771,874$ & 29.48 \\
$2016-2017$ & $4,502,129$ & 10.9 & $13,965,200$ & 32.24 & $15,391,669$ & 29.25 \\
$2017-2018$ & $5,086,493$ & 12.98 & $15,513,122$ & 32.79 & $17,098,304$ & 29.75 \\
$2018-2019$ & $5,741,765$ & 12.88 & $17,139,962$ & 33.5 & $18,971,237$ & 30.27 \\
\hline Source: Ministry of MSME. Annual Report (2020-2021).
\end{tabular}

Citation: Abhijit Kelkar. "Financial Management of Micro, Small and Medium Enterprises during COVID Times - Analytical Review with reference to Indian MSMEs". Medicon Engineering Themes 2.3 (2022): 12-25. 
The MSMEs sector's contribution to the country's gross value added (GVA) has been steadily expanding. Over time, the proportion of MSMEs in total GVA and total GDP has risen. In the country, there are 633.88 Lakh MSMEs involved in various economic activities. Manufacturing operations account for 31\% of MSMEs, while trade accounts for 36\%, and other services account for 33\%.

Within the identified sectors, micro-sector firms account for more than 99 percent of total estimated numbers, whereas small and medium-sized companies account for just 0.52 percent and 0.01 percent of total estimated MSMEs, respectively. Another factor to consider is that rural India accounts for $51 \%$ of all estimated MSMEs, while urban India accounts for $49 \%$. The following diagram depicts the ownership distribution of MSMEs in several sectors:

Male dominance in business ownership is seen in all fields, with males owning 79.63 percent of businesses compared to females owning 20.37 percent. Female ownership is more concentrated in rural regions, notably in microenterprises, than in metropolitan areas.

The following is a breakdown of MSMEs' ownership distribution by socioeconomic category:

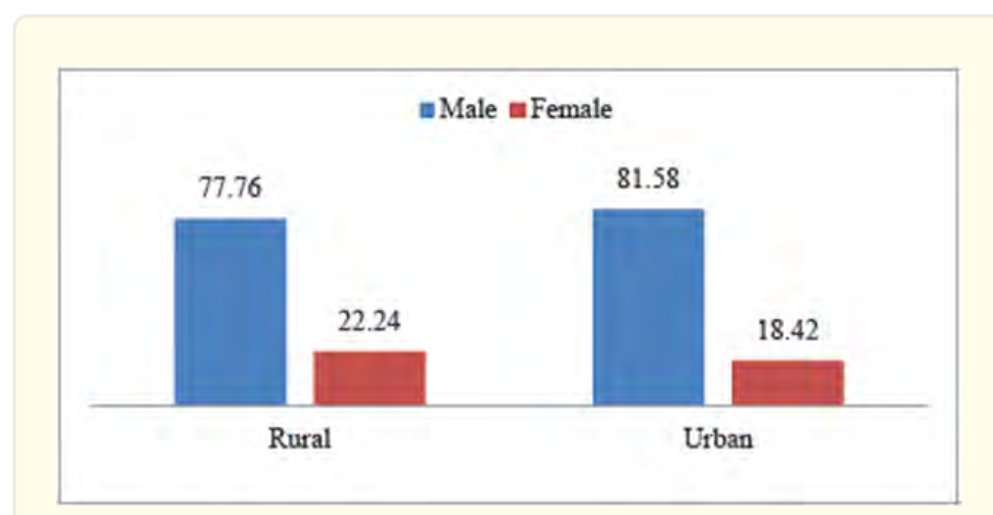

Figure 1: "Ownership distribution of MSMEs

Source: Ministry of MSMES, Annual Report (2020-2021)”.

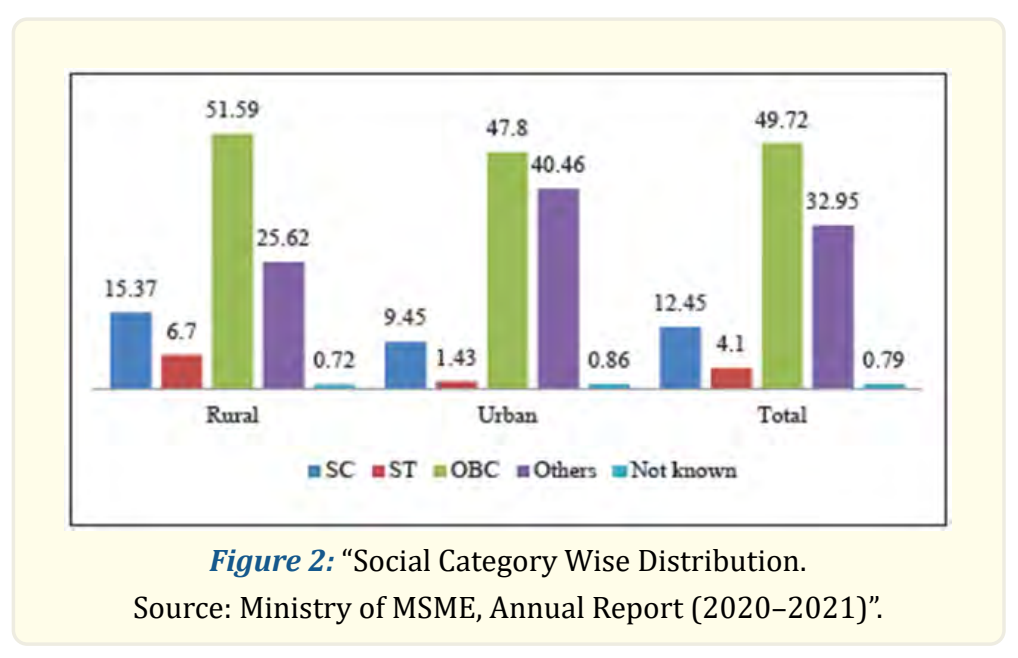

Citation: Abhijit Kelkar. "Financial Management of Micro, Small and Medium Enterprises during COVID Times - Analytical Review with reference to Indian MSMEs". Medicon Engineering Themes 2.3 (2022): 12-25. 


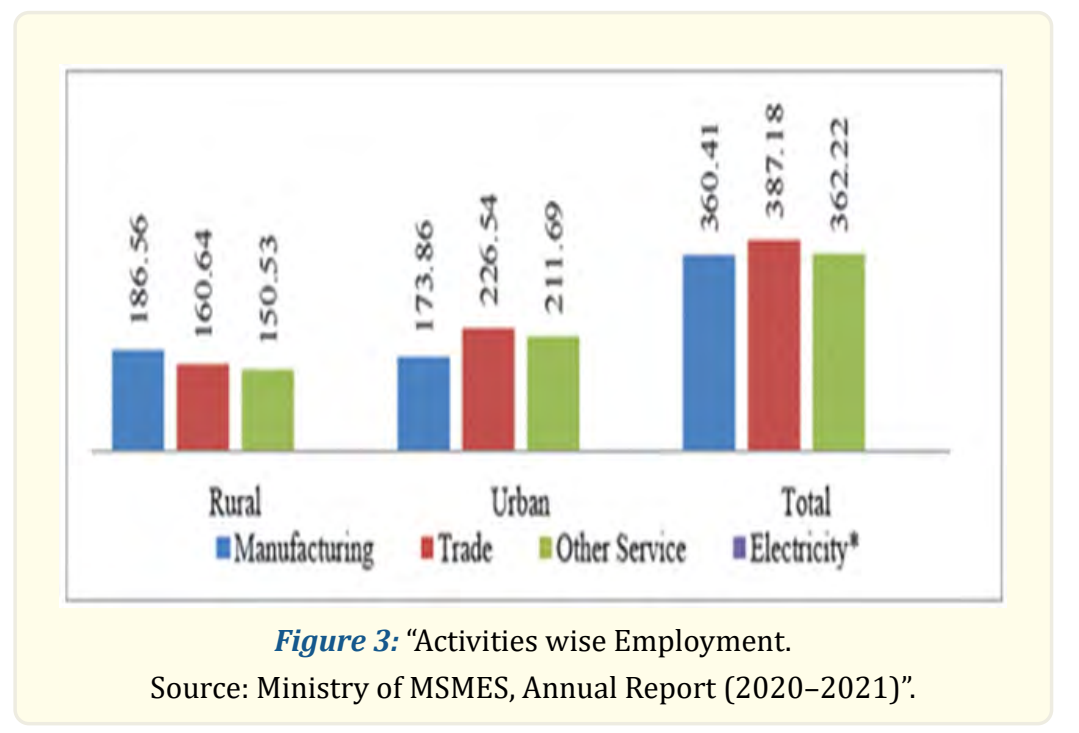

Socially backward individuals own 66.27 percent of all MSMEs (SC, ST and OBC). Many MSMEs are ascribed to OBCs owning them, particularly in rural and urban regions (49.72\%). Different sectors of the industry show the similar picture of category-wise distribution. "According to the NSS's 73rd round report, the MSMEs sector employs 1109.89 Lakh people across the nation, including 360.41 Lakh in manufacturing, 387.18 Lakh in trade, 362.22 Lakh in other services, and 0.07 Lakh in non-captive electricity generation and transmission".

Only the micro-sector employs 1076.19 Lakh people, accounting for almost 97 percent of overall employment, while the small and medium sectors employ 2.88 percent and 0.16 percent of the population, respectively. Male employees account for $844.68 \mathrm{Lakh}$ (76\%) of total employment, while female employees account for 264.92 Lakh (24\%).

The MSMEs sector's exports are very important in determining the country's overall export. Table 3 shows that when the export of MSMEs decreases, total export decreases as well. MSMEs account for approximately half of all exports in India.

“Share of MSMEs Export in Total Export (Amount in USD Million).”

\begin{tabular}{lccc}
\hline Year & Total Export & $\begin{array}{c}\text { Exports by } \\
\text { MSMEs }\end{array}$ & $\begin{array}{c}\text { Share of MSMEs Export in Percentage } \\
\text { (Rounded off) }\end{array}$ \\
\hline $2012-2013$ & 300,400 & 127,992 & 43 \\
$2013-2014$ & 314,415 & 133,313 & 42 \\
$2014-2015$ & 310,352 & 138,896 & 45 \\
$2015-2016$ & 262,291 & 130,768 & 50 \\
$2016-2017$ & 275,852 & 137,068 & 50 \\
$2017-2018$ & 303,376 & 147,390 & 49 \\
\hline
\end{tabular}

Source: RBI and PIB/DGCIS.

\section{Data Analysis \\ Correlation analysis}

Correlation analysis is a simple mathematical approach to determining the strength of a link between two variables. The most common application of correlation is to determine the exact degree of directional relationship between two variables. Their respective 
t-statistics and probability values are used to determine the significance degree of the relevant correlation.

To attain stationary in variance, all of the data series were changed to logarithmic form. The log transformation's theoretical purpose is to compare values in percentage terms. There are large variances in the number of MSMEs units in terms of output, investment, and employment; log transformation is required to linearize the extremes in variable variance. The following is the correlation equation between the variables:

$$
\begin{aligned}
& \text { LMSMEt }=\alpha_{0}+\alpha_{1} \text { LINVTt }+\alpha_{2} \text { LPRODt }+\alpha_{3} \text { LEMPLt }+u_{1 \mathrm{t}} \\
& \text { LINVTt }=\beta_{0}+\beta_{1} \text { LMSME } t+\beta_{2} \text { LPROD } t+\beta_{3} \text { LEMPLt }+\mathrm{u}_{2 \mathrm{t}} \\
& \text { LPRODt }=\gamma_{0}+\mathrm{y}_{1} \text { LMSMEt }+\gamma_{2} \text { LINVTt }+\gamma_{3} \text { LEMPL5 }+\mathrm{u}_{3 \mathrm{t}} \\
& \text { LEMPL } \mathrm{t}=\delta_{0}+\delta_{1} \mathrm{LMSMEt}+\delta_{2} \mathrm{LINVTt}+\delta_{3} \mathrm{LPRODt}+\mathrm{u}_{4 \mathrm{t}}
\end{aligned}
$$

Where $\alpha_{0}, \beta_{0}, \gamma_{0}$ and $\delta_{0}$ are intercept parameters, $\alpha_{1}, \alpha_{2}, \alpha_{3}, \beta_{1}, \beta_{2}, \beta_{3}, \gamma_{1}, \gamma_{2}, \gamma_{3}, \delta_{1}, \delta_{2}$ and $\delta_{3}$ are slope coefficients,

LMSMEs $=$ Log of MSMEs units

LINVT $=$ Investment

LPROD $=$ Production

LEMPL $=$ Employment

$u_{1,}, u_{2 t}, u_{3}$ and $u_{4}$ are error terms in Equations (1), (2), (3) and (4).

“No. of MSMEs, Employment, Investment and Production-Correlation Statistic 1992-2015.”

\begin{tabular}{|l|c|c|c|c|}
\hline Correlation t-statistic probability & LMSME & LINVT & LPROD & LEMPL \\
\hline LMSME & 1 & $0.997605 \mathrm{a}$ & & $0.999822 \mathrm{a}$ \\
\hline LINVT & & 1 & & $0.997783 \mathrm{a}$ \\
\hline LPROD & $0.973552 \mathrm{a}$ & $0.962728 \mathrm{a}$ & 1 & $0.974416 \mathrm{a}$ \\
\hline LEMPL & & & & 1 \\
\hline
\end{tabular}

Note: A Correlation is significant at the $1 \%$ level (two tailed).

Many macroeconomic time series variables exhibit trending or stationarity characteristics. Long-period study of variables with stationary features may provide erroneous results. The augmented Dickey-Fuller (ADF) test was performed on the selected data set to avoid stationarity.

Unit root test

\begin{tabular}{|l|c|c|c|c|}
\hline \multirow{2}{*}{ Variables } & \multicolumn{2}{|c|}{ At level } & \multicolumn{2}{c|}{$1^{\text {st }}$ difference } \\
\cline { 2 - 5 } & t-statistic & Probability & t-statistic & Probability \\
\hline LEMPL & 300010 & 0.9627 & -4.7017666 & 0.0012 \\
\hline LINVT & 0.498713 & 0.9726 & -4.393206 & 0.0026 \\
\hline LMSME & 0.215436 & 0.9572 & -4.755835 & 0.001 \\
\hline LPROD & 0.193875 & 0.9547 & -0.403116 & 0.777 \\
\hline
\end{tabular}

\section{Johansen co-integration analysis}

The Engel-Granger methodology is used to build the Johansen co-integration. The 1988 version of Johansen's co-integration test model is frequently used by researchers. This improved version of the Johansen co-integration test model may be used to examine the link between the rank of a matrix and the roots of its characters. For determining the long-run co-integrating connection among the 
variables, Johansen suggests two alternative likelihood ratio tests: the trace test and the maximum eigenvalue test. The following are the test statistics:

$$
\begin{aligned}
& \lambda \operatorname{trace}(r)=-T \sum i=r+1 n \ln (1-\lambda \mathrm{i}) \\
& \lambda \max (r+1)=-\mathrm{T} \ln (1-\lambda \mathrm{r})
\end{aligned}
$$

Where $\mathrm{T}=$ no. of observations

$\lambda=$ eigenvalues or approximated values for characteristic roots

$r=$ co-integration rank

The variables for study here seem to be log MSMEs, log employment, \& log investment.

\section{Co-integration Rank Test (trace)}

\begin{tabular}{|l|c|c|c|c|}
\hline Hypothesized no. of CE(s) & Eigen value & Trace statistic & 0.05 Critical value & Probability $^{\boldsymbol{a}}$ \\
\hline None $^{\text {b }}$ & 0.767388 & 50.20134 & 34.19165 & 0.0004 \\
\hline At most $^{\text {b }}$ & 0.491388 & 19.46448 & 19.26074 & 0.0344 \\
\hline At most 2 & 0.26131 & 6.272532 & 8.153436 & 0.1535 \\
\hline
\end{tabular}

Note: Trace test indicates two co integrating equations at the 0.05 level.

a MacKinnon et.al. (1999)

b denotes rejection of the hypothesis at the 0.05 level.

Johansen presents a sequential testing approach for determining the number of co-integrating relationships in a consistent manner. "To begin, compare $\mathrm{H0}(\mathrm{r}=0)$ to $\mathrm{H} 1(\mathrm{r}>0)$, where $\mathrm{r}$ denotes the number of co-integrating relationships between variables." If this null is not rejected, it is concluded that the variables do not have co-integrating relationships. If H0 ( $r=0$ ) is rejected, it is assumed that at least one co-integrating relationship exists, then $\mathrm{HO}(\mathrm{r}=1)$ is tested against $\mathrm{H} 1(\mathrm{r}>1)$. If the null hypothesis is not rejected, it is assumed that just one co-integrating connection exists. If the null hypothesis is rejected, it is assumed that at least two co-integrating relationships exist. Until the null is not rejected, the sequential procedure is repeated.

\section{Co-integration Rank Test (Maximum Eigenvalue)}

\begin{tabular}{|l|c|c|c|c|}
\hline Hypothesized no. of CE(s) & Eigen value & Max - Eigen statistic & 0.05 Critical value & Probability $^{\boldsymbol{a}}$ \\
\hline None $^{\mathrm{b}}$ & 0.767388 & $29.53 \%$ & 21.29852 & 0.0025 \\
\hline At most 1 & 0.491388 & 13.20102 & 15.8911 & 0.0801 \\
\hline At most 2 & 0.26131 & 6.272532 & 8.153436 & 0.1535 \\
\hline
\end{tabular}

Max-eigenvalue test indicates co-integrating equation(s) at the 0.05 level.

a MacKinnon-Haug-Michelis (1999) p-values.

b Denotes rejection of the hypothesis at the 0.05 level.

\section{Results of the Statistical Analysis}

1. The correlation data for MSME units, production, employment, and investment suggested that the variables are substantially connected. The LMSME and LEMPL coefficients (0.999) are statistically significant and have a high degree of positive association. "Similarly, there is a statistically significant positive association between LMSME and LINVT (0.997) and LINVT and LEMPL (0.997). Furthermore, the correlation values between LPROD and LEMPL, LMSME, and LINVT $(0.974,0.973$, and 0.962, respectively)" show a strong positive association between the variables.

2. Unit root test summarization clearly indicates the employment, investment, and MSMEs units were non-stationary just at level, but then become stationary on the very first variance, I (1), at the $1 \%$ significant level while using the logarithmic transformation 
of MSME units, employment, investment, or production again for unit root test." However, unlike the first distinction, production is not stagnant at this level. In order to account for the second difference, an instrumental variable must be used as a proxy for production. To evaluate the long-term link, we simply look at three variables: employment, investment, and MSMEs units.

3. Co-integration Rank Test (trace) Table shows that the probability values 0.0004 and 0.0344 , respectively, are statistically significant at none and at most 1 . These results show that the null hypothesis is rejected, implying that these three variables have a long-term co-integrating relationship. As a result, there's no need to check at least 2.

4. Co-integration Rank Test (maximum eigenvalue) indicates that the null hypothesis and testing technique for the maximum eigenvalue test are the same as for the trace statistic. The null hypothesis is rejected since the probability value (0.0025) is less than 5 . This indicates that the variables are co-integrated in the long term. There is no need to check at most 1 and most 2 after the null hypothesis is rejected.

\section{Findings \& Conclusions}

For MSMEs, India's key aim is 'from local to global.' The majority of Indian MSMEs are located in rural areas, which will play an important role in making India self-reliant.

The impact of changing the definition of a small business on its economic performance has yet to be studied, and it will be in the future. This definition should almost probably boost the number of MSME units, which also will result in more production, employment, product diversification, investment, and export.

While looking at the important components of both the MSMEs sector empirically, it really is obvious that perhaps the variables had a significant positive relationship (MSME units, production, employment and investment).

Johansen's co-integration analysis rejects that null hypothesis to use the trace test and maximum eigenvalue test, suggesting that perhaps the presence of a long co-integrating relationship.

The preponderance of MSMEs were having problems securing funding and promoting their products throughout COVID-19. Salaries, electricity bills, rent, property \& water taxes, phone and internet fees, and bank loans are just a lot of small things consumers have to deal with. As a result, fundamental issues including such registration, credit limitations, marketing hurdles, technological acceptance, and inadequate infrastructural facilities, among others, must be addressed over time.

Considering the widespread havoc that COVID-19 has wreaked, to reestablish faith in the MSMEs sector, the government should build an ongoing monitoring process and announce urgent corrective steps. 'Make in India' and 'Digital India' would inspire even more individuals.

MSMEs should indeed be encouraged to connect to the internet, while fiscal incentives for this sector should be strengthened. So Indian government could take several initiatives to enhance Indian SMEs \& achieve the goal of making India self-sufficient.

\section{Recommendations \& Suggestions}

MSMEs must have access to their financial position and security. Given that the majority of businesses are suffering financial difficulties, the agencies financing MSMEs should consider providing loans to these companies to assist them in navigating the present crisis. Low-interest loans with extended payback terms may be available. The lending limit for MSMEs should also be enhanced. To ease the load, loan repayments may be reduced. Regular financial flows to entrepreneurs of MSMEs should be ensured. Payment delays in SMEs should be converted into the convenient periodical installments rather than penalizing them heavily. Financial management of the MSMEs should also be very keen especially in terms of the following factors:

1. Budgets.

2. Predicted Cash Inflows and Outflows.

3. Anticipation of the Risks and probable Remedial Measures.

Citation: Abhijit Kelkar. "Financial Management of Micro, Small and Medium Enterprises during COVID Times - Analytical Review with reference to Indian MSMEs". Medicon Engineering Themes 2.3 (2022): 12-25. 
4. Focus and Emphasis on the preparation, implementation and assessment of the short term plans of duration between 3 to 6 months in place of the long term plans.

Before creating and implementing a financial strategy, it is vital to have reliable and accurate information regarding the government's financial relief package and the help supplied by trade organizations.

MSMEs must reconsider their goods, differentiators, distribution channels, product quality, and other strategies. MSMEs must examine its operations in order to design a COVID-19 operational strategy. While consumers' discretionary spending is evident, there is a distinct shift in consumer preferences that may be taken advantage off. The creation of a strong digital ecosystem becomes critical. New ideas are transforming the business world. MSMEs should communicate with consumers and suppliers across more places and activities through the new technology.

The government's e-Marketplace (GeM) was designed to encourage MSMEs to participate in government procurement of goods and services. In provided by online sales, a strong and favourable social media presence would benefit customer and stakeholder participation. Creating a digitally active internal atmosphere that facilitates enabling remote work or homework without endangering data security or staff productivity is also a smart idea. It's indeed vital to incorporate new-age technological advancements into MSMEs. Technology adoption can assist MSMEs through enhancing process efficiency, lowering costs, expanding information visibility, or increasing worker safety. Collaboration with technology experts, such as research institutes, tech start-ups, and students, may help MSMEs create new products and processes. MSMEs may benefit from forming partnerships. It might partner alongside existing multinational companies to penetrate into the Indian market or set up a low-cost manufacturing base. Work throughout three shifts and preserve social distance during work to revive a sector that has struggled since the COVID-19 epidemic. It ILO recommends that government measures focus on worker safety, economic stimulation, including income and employment assistance. (ILO, 2020). MSMEs can conduct business transactions via internet banking instead of meeting in person. The above allows companies to cut transaction costs even while speeding higher transaction process. It's vital to learn from recent crises and develop a crisis management strategy that can deal with the both immediate or long-term consequences.

MSMEs can also manage the cash challenges through different ways:

- Be proactive rather than reactive - Map your business cashflows under different scenarios for FY21 and the next two financial years. For example - If business recommences in Sep'20 at 50\% of revenue or in Dec'20 at $80 \%$ of revenue, then you must account for what the overall cashflows would look like. MSMEs should conserve cash and reduce leverage wherever possible.

- Negotiate fixed expenses with all vendors to cut costs and reduce Opex - Re-evaluate all fixed expenses to find any possible savings. Re-negotiate with all vendors for a waiver/discount /deferment of payments. Vendors today are happy to renegotiate than lose a good customer. Renegotiate office rentals; think of sub-letting your bigger office or moving to a smaller space to augment your cashflows.

- Stakeholder management - Keep in regular touch with all your key stakeholders and try to support them as much as possible. Out of sight is out of mind.

- Reinvent yourself - Explore newer ways to serve your customers once the market recovers. Is there any horizontal or vertical diversification opportunity? Are there any new geographies you can serve; products you can launch or strategic tie-ups possible? The current lockdown is the opportunity to strategize and re-invent like no other.

- Develop teams - Build and encourage your teams and use this time to upskill/reskill your teams and prepare them for the new ways of working in the post-corona world. Pay their salaries on time and check on their physical, social, and emotional well-being regularly.

- Make an informed choice before taking advantage of the loan moratorium - The RBI has announced a three-month moratorium on term loans or working capital constraints, but it is important to make an educated judgment before taking advantage of it. An important aspect is that the moratorium is only a deferment of EMI/Interest dues and not a waiver, which means interest for the moratorium period will continue to accrue leading to an increase in number of EMIs depending upon the type of loan, interest

Citation: Abhijit Kelkar. "Financial Management of Micro, Small and Medium Enterprises during COVID Times - Analytical Review with reference to Indian MSMEs". Medicon Engineering Themes 2.3 (2022): 12-25. 
and the remaining tenure.

- If they can afford the EMI, skip the moratorium. The additional expenditures of moratorium interest aren't worth the advantage.

- In case of multiple loans, consider factors like: interest charged, number of pending instalments, nature of loan - fixed vs floating, part payment and foreclosure terms into consideration while deciding which loan should be opted for moratorium. Do not opt for moratorium if the remaining loan tenor is very high as that will lead to additional interest cost over the life of the loan.

- In case your balance sheet has instruments like loans from MFs, NCDs, MLDs, AIF etc. which don't come under the moratorium relief then prioritize payments for these and take moratorium for other loans if required, while keeping your overall cashflow position in mind.

- If you have any fixed or other deposits with lower returns, then you must evaluate a proper tradeoff comparison of additional cost that you will end up paying if moratorium is opted against interest earned on such deposits. It is advisable to pay EMI of your loans by doing a pre-mature withdrawal of your deposits if the net post tax return on your deposits is less compared to your loan interest rate (Khanna, 2020).

\section{References}

1. Ali A and Husain F. "MSMEs in India: Problems, solutions and prospectus in present scenario". International Journal of Engineering and Management Sciences 5.2 (2014): 109-115.

2. Banu S and Suresh B. "COVID-19 and its impact on micro, small and medium enterprises in India". Mukt Shabd Journal IX.X (2020): 606-617.

3. Bhuyan U. "A study on the performance of micro, small and medium enterprises in India". Global Journal of Management and Business Research: A Administration and Management 16.9 (2016): 32-36.

4. Chauhan JP. "An impact of COVID-19 on Indian economy: A brief view of selected sectors". EPRA International Journal of Multidisciplinary Research (IJMR) 6.6 (2020): 9-12.

5. Das K. "Micro, small and medium enterprises in India: Unfair fare". Gujarat Institute of Development Research, Working Paper No 181.5 (2008): 1-29.

6. Eniola A and Entebang H. "Government policy and performance of small and medium business management". International Journal of Academic Research in Business Social Science 5.2 (2015): 237-248.

7. Ghosh S. "Examining the COVID-19 relief package for MSMEs”. Economic \& Political Weekly, LVn22 (2020): 10-12.

8. Hariharan A, Thomas S and Visvanathan P. "Impact of COVID-19 on the performance of micro, small and medium enterprises (MSMEs) in India: A case study in Kerala”. Annals of R.S.C.B 25.4 (2021): 14797-14816.

9. Indrakumar D. "COVID-19 and its impact on Micro, Small and Medium Enterprises in India". Manpower Journal, LIV (3\&4) (2020): 75-88.

10. International Labour Organization (ILO). COVID-19 and the world of work: Impact and policy responses. ILO Monitor (2020).

11. MacKinnon J, Haug A and Michelis L. "Numerical distribution functions of likelihood ratio tests for cointegration". Journal of Applied Econometrics 14.5 (1999): 563-577.

12. Kishore S. "Growth of micro, small and medium enterprises in India". BIMS International Journal of SocialScience Research 1.2 (2016): 6-13.

13. Kumar NK and Sardar G. "Competitive performance of micro, small and medium enterprises in India”. Asia-Pacific Journal of Social Sciences III.1 (2011): 128-146.

14. Ministry of Micro, Small and Medium Enterprises (MSMEs). The micro, small and medium enterprises development act (2006).

15. Ministry of MSMEs. Annual report (2018-2019). Government of India.

16. Ministry of MSMEs. Annual report (2020-2021). Government of India.

17. Prasad R and Mondal A. "Impact of COVID-19 pandemic on Indian economy with special reference to Indian MSMEs sector". Research Gate XV.7 (2020): 16-21.

18. Raney HM. “COVID-19 pandemic: Impact on MSMEs”. Studies in Indian Place Names 40.68 (2020): 396-401.

Citation: Abhijit Kelkar. "Financial Management of Micro, Small and Medium Enterprises during COVID Times - Analytical Review with reference to Indian MSMEs". Medicon Engineering Themes 2.3 (2022): 12-25. 
19. Rathore U. "From slowdown to lockdown: Effects of the COVID-19 crisis on small firms in India". Oxford Policy Management (2020): 1-32.

20. Reddy K, Sasidharan S and Raj R. "Revitalizing MSMEs”. YOJANA 64.11 (2020): 24-29.

21. Roy S. "First to be hit by the pandemic: This sector will take years to make up for the losses". The Economic Times (2020).

22. Singh A. What about India's MSME Sector: COVID-19 pandemic and Indian MSMEs sector outlook (2020).

23. Sipahi E. "COVID-19 and MSMEs: A revival framework". Research Journal in Advanced Humanities 1.2 (2020): 7-21.

24. The Hindu. MSMEs will be the biggest casualty of COVID-19 in India: study (2020).

25. Tripathy A. COVID-19 affect and micro, small, and medium enterprises (p. 5). The Times of India (2020).

26. Tripathy S and Bisoyi T. "Detrimental impact of COVID-19 pandemic on micro, small and medium enterprisesin India”. Jharkhand Journal of Development and Management Studies 19.1 (2021): 8651-8660.

27. Vaishnav A and Surya S. “Definition of MSMEs”. PRS Legislative Research XV.9 (2020): 1-12.

28. Vashisht A and Chaudhary A Priyanka. "Role of SMEs in Indian economy". International Journal of Management 3.1 (2016): 14-18.

29. WTO. Helping MSMEs navigate the COVID-19 crisis. World Trade Organization LXV.12 (2020): 1-8.

30. World Bank Group. Financing India's MSMEs. International Financial Corporation (2018).

\section{Volume 2 Issue 3 March 2022}

(C) All rights are reserved by Abhijit Kelkar. 